\title{
The Internet - A fad or a fundamental for relationship marketing
}

Received (in revised form): 22nd April, 2000

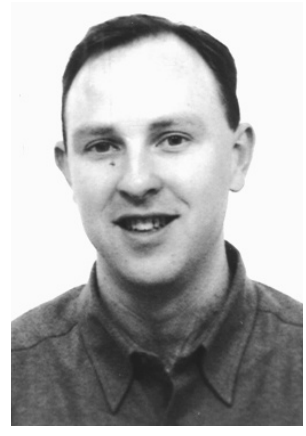

\section{Stuart Allan}

has been working in the IT industry for 16 years. During this time he has held a variety of technical and managerial positions. $\mathrm{He}$ is currently an IT manager working for the Royal Bank of Scotland.

\section{Farooq Chudry}

is a senior lecturer at the University of the West of England teaching direct marketing. He has over 20 years' experience in empirical research and IT. His research interests include investigating consumer behaviour across cultures.

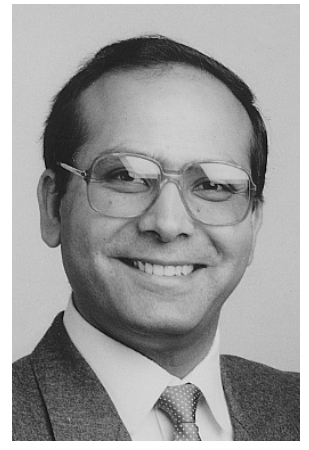

Abstract It is recognised that deciding on how to deal with the Internet is one of the major strategic challenges that businesses face today. Within a short period, the Internet has emerged from being a niche medium used by a minority of individuals, to being a mainstream channel used by millions of people and businesses globally. Moreover, the Internet is being used to gain competitive commercial advantage worldwide, removing market and geographical barriers of entry. This study examines the attitude of business-to-consumer companies towards the use of the Internet in order to establish whether it is simply fashionable to use this medium or whether it is a fundamental for successful relationship marketing. To supplement a literature review a postal survey was conducted among all the client companies of Prime Response, a major supplier of database marketing software for customer relationship marketing (CRM). A total of eleven companies (31 per cent of the census) took part in the study. The research concludes by suggesting that the Internet is both a fad and a fundamental for relationship marketing at the moment. It is recommended that the Internet should be used as an integral part of a business's overall strategy and, as a channel, managed in conjunction with all other channels that a business uses.

\section{INTRODUCTION}

It has been suggested that 'the Internet will be the best relationship marketing tool ever, as it offers opportunities for direct marketers to understand their customer's needs and to establish personal relationships'. ${ }^{1}$ The purpose of this paper is to explore this perspective through undertaking research with a cross-section of businesses operating in different business sectors.
It is widely accepted that the 4Ps of marketing is the basic framework that has underpinned most marketing activities over the last 30 years. ${ }^{2-4}$ The notion of the 4Ps was conceptualised by McCarthy ${ }^{5}$ from Borden's 'marketing mix'. The underlying premise of the 4Ps is its transactional nature; it sets out to achieve a sale and so long as the sale is made the marketing programme has, to all intents and purposes, achieved its 
objective. That is to say the marketing programme has identified the customer's need for a particular product or service, and persuaded the customer through whatever means (price, advertising, etc.) to make a purchase. No consideration is given, however, to how satisfied the customer is following the sale in terms of their experience of purchasing or consuming the product or service, or whether they are likely to return at some point for repeat business or recommend the supplier to others. Thus customer retention is often more by default than by design.

Figure 1 outlines different levels of customer loyalty - transactional marketing efforts typically concentrate on the bottom two rungs of this ladder (prospect and customer), the emphasis being on securing new customers and selling to those customers with little or no importance given to customer retention. Relationship marketing, however, is more interested in the top three rungs of the ladder (client, supporter and advocate) - retaining customers and enhancing the relationships a company has with its customers.

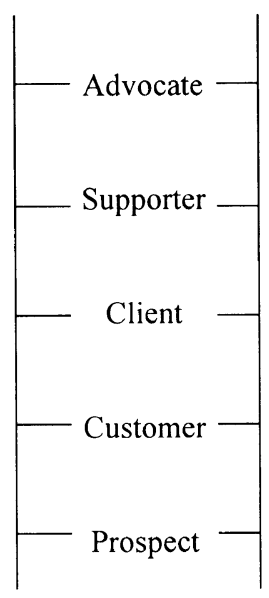

Figure 1: Customer loyalty ladder ${ }^{7}$
Peltier, Schibrowsky and Davis, ${ }^{8}$ O'Malley et al, ${ }^{9}$ and Gronroos ${ }^{10}$ broadly agree the following requirements to implement a successful relationship marketing strategy:

- a database has to be used to store all details about customers and it has to be maintained with up-to-date and accurate information

- customers must be recognised as individuals, and their particular needs satisfied and dealt with in a consistent manner that is amenable to the customer

- high levels of customer satisfaction must be implemented throughout the whole of its organisation

- a quality control or other type of system needs to be developed to monitor and measure customer satisfaction

- an 'end to end' process that consistently operates to common standards must replace any individual functional tasks that are in operation. If partnerships are established to deliver any part of the service, the end to end process must be delivered seamlessly by all third parties too.

Relationship marketing's primary purpose is to build a long-term relationship with the customer that in turn should result in repeat business. Successful relationship marketing, however, requires all aspects of an organisation to take joint responsibility for this goal, and to a large extent, therefore, depends on the attitudes, commitment and performance of all its employees, agents and partners. ${ }^{11}$

There is no single, universally accepted, definition of what the Internet is. Hamill and Gregory view the Internet as 'a global network of interlinked computers operating on a standard protocol that allows data to be transferred between otherwise 
incompatible machines'. ${ }^{12}$ Ellsworth and Ellsworth regard it as 'a digital communications network connecting multiple networks from many countries throughout the world'. ${ }^{13}$ According to Kressin the Internet is simply 'a network of networks'. ${ }^{14}$ The consistency of these descriptions, however, lies in the basic concept of the Internet - a medium that allows users of computers (or other such devices) attached to it to communicate and exchange information with one another wherever they are in a timely fashion.

The key to understanding the Internet is the concept of connectivity. ${ }^{15}$ The Internet provides a communications capability to allow companies to communicate with existing, previous and potential customers. It should not, therefore, be seen as just another delivery channel. The real opportunity on the Internet is not just doing what you have always done cheaper and faster, but instead the real opportunity is to rethink at a fundamental level the business models that you employ on this new platform, both in terms of what kind of value you can deliver to your customers and also the kinds of relationships that you can build with customers'. ${ }^{16}$

It is further suggested that the Internet's unique characteristics indicate that it will 'have a profound impact on the study and practice of international marketing'. ${ }^{17}$ Ellsworth and Ellsworth note that "compared with traditional marketing communication channels, the WWW is faster, less expensive, round the clock and global'. ${ }^{18}$ It is also interactive — 'interactive media allows for unprecedented opportunities for a marketer to relate to a consumer'. ${ }^{19}$ This is consistent with the belief that the interactive characteristics of the Internet also enable marketers to move away from 'one-to-many' communication models with their customers to 'many-to-many' communication models, as it becomes considerably easier for recipients of marketing messages to respond instantaneously. ${ }^{20}$

The key to successful exploitation of the Internet will therefore centre on harnessing the power of its strengths and repackaging appropriate business solutions that will take full advantage of the Internet's unique characteristics.

\section{AIM}

The aim of the research is to deduce the benefits that companies have realised from using such a modus operandi, and provide an indicator as to the importance that relationship marketing techniques may have when used in conjunction with the Internet.

\section{RESEARCH OBJECTIVES}

This study is designed to investigate:

- how companies are using the Internet, in the context of relationship marketing

- the level at which companies have integrated their Internet offerings with the rest of their core businesses since relationship marketing requires a seamless end to end process for dealing with all forms of customer interaction

- the importance companies place on each of the unique characteristics of the Internet and the ways in which companies are using the different applications that are available on the Internet for relationship marketing purposes.

\section{RESEARCH METHODOLOGY}

Despite the pace at which the Internet has developed in recent years, it is still very much a new phenomenon. 
Appraising any benefits gained through long-term relationships, as a direct result of using the Internet, is extremely difficult to prove in an empirical fashion, which requires the measurement of exact data.

The nature of this enquiry is predominantly qualitative, measuring the responding companies' attitudes towards using the Internet for relationship marketing, and their subjective views of any benefits that they believe they have realised as a result of adopting such a marketing strategy.

\section{DATA COLLECTION}

The primary data were collected using a postal questionnaire, which was sent to a number of different companies operating within different business sectors. All of the companies targeted were existing customers of Prime Response ${ }^{21}$ in the UK, Europe and South Africa.

As a prelude to developing the measuring instrument (self-completion postal questionnaires), an in-depth, semi-structured interview was undertaken with a managing consultant from Prime Response. This was helpful in providing both content and construct validity.

\section{Sampling method}

All 35 client companies of Prime Response were targeted with the questionnaire. Eleven of these companies responded (a response rate of 31 per cent).

\section{DATA ANALYSIS AND SYNTHESIS}

Of the companies that responded, it is not surprising that all are using the Internet in some shape or form (see below). All respondents indicated they are using the Internet for e-mail and have a website. Most are using the
Internet for some form of e-commerce and just over half use the Internet for advertising purposes. Customer support is the next most popular service with just over a third of respondents indicating that they use the Internet for this, with smaller percentages indicating that the Internet is also used by some companies for data transfer, newsgroups, newsletters and on-line catalogues.

The phrase 'interactive marketing' was used in the questionnaire specifically to differentiate marketing activities associated with the Internet from other more traditional forms of marketing. The results highlighted that less than half of the respondents who use Internet e-mail use it for interactive marketing. E-mail is the most popular service used on the Internet. ${ }^{22}$ Thus it is not surprising there is such a large gap between a company's use of the Internet and the extent to which they are using it for marketing purposes. E-mail has a considerable potential, however, as a marketing tool. 'Well formatted attractive e-mails will help companies both garner new sales and also offer customised marketing messages to existing clients. ${ }^{23}$ Companies are not, therefore, exploiting the full potential of this characteristic of the Internet.

This theme of companies not using the Internet solely for interactive marketing is common among all the Internet characteristics. According to the responses, the two most prevalent Internet services used for interactive marketing are websites and e-commerce. Respondents to the questionnaire valued most the immediate/direct interaction capability of the Internet, reinforcing the fact that the Internet can be used as a powerful communication mechanism. From a relationship marketing viewpoint it is important that companies are able to communicate with their customers on an individual basis. ${ }^{24}$ 


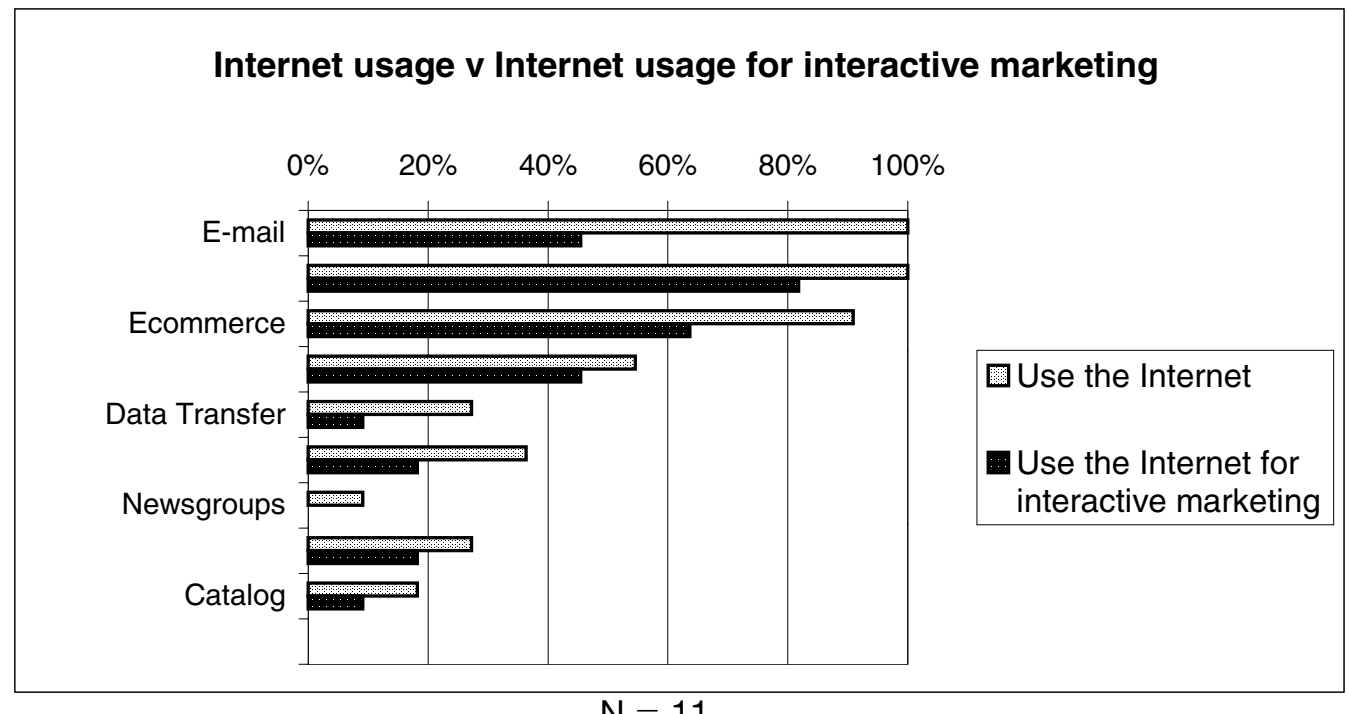

$\mathrm{N}=11$

Figure 2: Profile of Internet usage from respondents to the survey

Key finding 1: The Internet therefore provides an ideal vehicle for building and maintaining personalised customer relationships.

Overall, getting to know customers better was seen as one of the lowest benefits to be realised through using the Internet. One explanation for this could be that companies do not yet have large numbers of customers using the Internet, and therefore have not invested large amounts of time or money considering how to build and maintain relationships with customers. Moreover, some organisations are using the Internet as an additional channel to complement already established forms of conducting business.

Relationships may, therefore, be maintained via other channels since every contact a customer has with a company contributes to that customer's overall view of that organisation. ${ }^{25}$ Thus, if companies ignore the Internet as a relationship enhancing medium, it may result in, at best, a customer not choosing to use a company's Internet offering, and, at worst, a company losing that customer.

Prime Response's managing consultant suggests the Internet has the makings to be a major contributor for communicating with customers individually:

'the potential for targeting is absolutely huge. I don't think we've even started to scratch the surface of what could be done there.'

One respondent indicated they had benefited in getting to know their customers better via the Internet but did not specifically state how they were doing this. From other comments this company made on the questionnaire, however, it has invested in monitoring 'hits' on its website. It has also combined all communication and transaction methods it uses across all channels and it claims this has resulted in significant cross-selling opportunities. Increased cross-selling opportunities were cited as the prime benefit realised through using the Internet (equal with providing better customer service). 
Key finding 2: Thus it can be concluded that if companies develop their Internet strategy as an integral part of their overall business strategy, significant benefits can be realised.

Cross-selling is regarded as a direct benefit from understanding customer's needs. ${ }^{26,27}$ Therefore, if companies are not using the Internet to nurture their relationships with their customers and understand their needs more intimately, they are perhaps not achieving the levels of cross-selling they could. Or simply put another way, even though companies have benefited in increasing cross-selling opportunities through using the Internet, they could benefit even more if they used the Internet to get to know their customers better by capturing more information and details about their customers. ${ }^{28}$

Interestingly, all the respondents to the questionnaire described themselves as being in the services sector, even the general retailers that responded who would have traditionally been seen within the products sector. This is further evidence of the blurring of conventional service companies and product companies. Retailers no longer compete by just selling products, they must be able to provide an effective customer service support infrastructure around their core business, to the point where this is now often deemed more important than selling the actual product. From a relationship marketing perspective, this movement towards all types of companies being seen as part of the services sector can be viewed as a positive change. High levels of customer satisfaction are a key requirement for companies adopting relationship marketing techniques. ${ }^{29-32}$ Recognition of the need to service the customer before, during and after any purchase, will inevitably lead to increased customer satisfaction, as long as it is delivered to consistently high standards. If companies have made the investment and transition to be customer facing, then this is potentially one way companies can differentiate themselves from their competitors.

Achieving high levels of customer satisfaction with Internet customers poses different challenges, however. By default, there is no direct human interaction, and that may not appeal to all customers. As Prime Response's managing consultant says:

\footnotetext{
'Some customers will probably love the idea of not actually having to talk to anyone and work within a customer service front end web site, but others will want to go into a branch or speak to someone within a call centre, and have service provided in that way.'
}

For those customers who wish to interact over the Internet 'there is substantial evidence that, despite the lack of face-to-face or even voice contact, an IT-based relationship does not inhibit the formation of high levels of trust, satisfaction, and commitment between buyer and seller'. ${ }^{33}$ Trust, satisfaction and commitment are key elements in developing a successful relationship between a buyer and a seller. ${ }^{34,35}$ We can therefore surmise that the use of the Internet does not preclude strong relationships between such parties from being developed.

Key finding 3: Respondents to the questionnaire viewed the Internet as enabling them to provide better customer service as the top benefit realised to date (equal with increased cross-selling opportunities).

Even some of those companies, who today did not see the Internet as providing better customer service, still 
saw it as having significant potential for the future. Paradoxically, although providing better customer service was overall the equal top benefit that companies said that they had realised from using the Internet, the number of companies actually using the Internet for customer support was quite low (just over a third). This suggests companies are either using the Internet more for transactional purposes and, in doing so, aiming to improve customer satisfaction, or giving greater accessibility to customers.

The Internet enables customers to contact companies at any time, as opposed to when a branch may be open or a call centre manned. ${ }^{36}$ This perspective can be supported by the fact that the second most important Internet characteristic, viewed by the respondents, was its accessibility 24 hours a day, seven days a week. Companies are potentially missing an opportunity to move their customer support infrastructures onto the Internet, or at least offer this as an alternative channel, in order to improve customer satisfaction for those customers who have access to the Internet. One easy option companies could offer, for example, is to place a list of frequently asked questions about their products or services on their website. While this may not resolve all customers' queries, they can at least be accessed 24 hours a day, seven days a week, a benefit which most companies are unable to offer using other means in a cost-effective fashion.

Respondents viewed the Internet as helping companies to reduce their costs as another key benefit. Interestingly, although reducing costs was the third highest benefit companies claimed they had realised through using the Internet, most respondents commented that as a result of using the Internet, their costs have actually increased. It would be reasonable to assume that over time companies are expecting to see their costs reduce as a result of using the Internet. ${ }^{37,38}$ This is also supported by Prime Response's managing consultant.

'in the longer term there is certainly an opportunity there to reduce costs, just as the move away from branches to call centres has done. From a marketing perspective a web site, an e-commerce transaction, or an email - all are much cheaper interactions, from a cost perspective.'

Using Likert's ${ }^{39}$ rating scale, an overall perspective of the respondents' attitudes to the Internet as a marketing medium was ascertained. This in turn was compared with a summary of the benefits that respondents have realised through using the Internet for marketing purposes within their companies. By comparing these two perspectives it can be seen that when asked to comment on the benefits the Internet has for marketing purposes, all the respondents were either very positive or positive in their assessment. Realising any benefits, however, highlighted a very different view, with over half of the respondents indicating they had a negative opinion towards this.

Key finding 4: The Internet therefore is seen as having significant potential for marketing purposes, but to date, the companies surveyed have not started to fully realise these benefits.

One explanation for this could be that companies are not analysing the data they are accumulating through interactive marketing as they do not have in-house expertise in interactive marketing, and, therefore, do not understand how to interpret any findings. Almost all the respondents indicated that they had found it difficult to recruit experienced staff in interactive marketing. Prime 


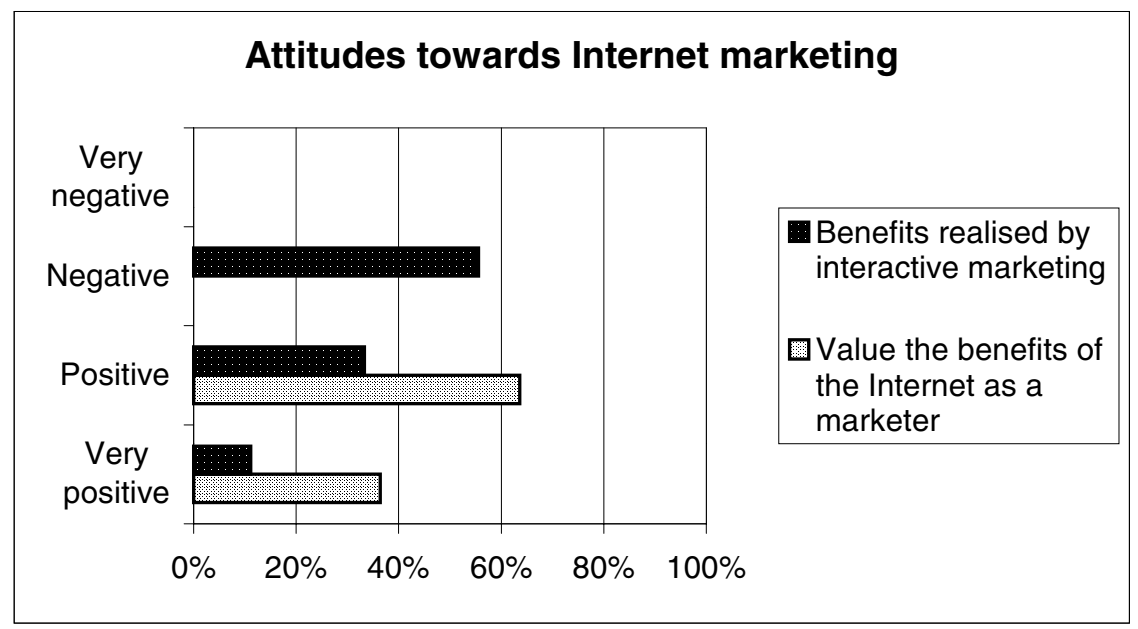

$N=11$

Figure 3: Attitudes towards Internet marketing

Response's managing consultant, who highlights the need for specialised skills, supports this view:

'it requires a different mindset ... you really do need to understand data, you need to understand data structures, you need to understand the IT perspectives and that's where it's very scientific.'

Without suitably qualified staff, companies will find it difficult to evaluate and understand any benefits they can gain or have gained through these new channels.

An alternative hypothesis could be that the profile of companies that responded to the questionnaire also had some bearing on the reason why companies have not yet fully realised the benefits of marketing via the Internet. The companies that responded to the questionnaire were primarily all large in terms of turnover and number of employees. Although there is no evidence from the data, Prime Response's managing consultant does suggest the age and size of a company has some bearing on the readiness with which companies can make the transition to new forms of marketing. He goes on to infer, however, that the more established companies will probably have access to larger volumes of data and are therefore more likely to be able to draw more pertinent conclusions once they start to analyse their data. This observation further reinforces the potential lost opportunity for those companies that responded to the questionnaire, in terms of not attempting to construe any meaning from their Internet marketing activities.

Of the responses, almost one-fifth indicated that they were not using the Internet for marketing purposes today. Interestingly, these were also within the financial services sector, the sector identified by Prime Response's managing consultant as traditionally the strongest at database marketing - a major prerequisite for relationship marketing. ${ }^{40}$ These companies all indicated, however, that they expected to start using the Internet for marketing purposes within the next 12 months. This provides evidence that even those organisations that are not currently using the Internet 
for marketing purposes are placing great importance on using it in the very near future.

It is vitally important for up-to-date information about all customer contacts to be readily accessible by all employees. ${ }^{41}$ It is further suggested that some companies are successfully using Internet-type technology (an Intranet) to do this. Prime Response's managing consultant supports this view too:

'I think one of the big things about the Internet, is actually what an Intranet can do for distributing information about customers internally within an organisation, getting the right piece of information to the right member of staff serving customers at the right time.'

In the context of relationship marketing, companies are not taking advantage of the Internet's capabilities to store or disseminate up-to-date customer information easily, although companies may legitimately have other systems (non-Internet-based) that enable them to do this. The key requirement, however, is that pertinent details are recorded for customers interacting using the Internet, along with any other forms of interaction (ie visits to a branch, calls to a call centre, etc.). The fact that the customer interaction over the Internet is both to and from a computer system makes it relatively easy to capture details of that interaction. The greater challenge companies face, however, is to take that information and combine it with existing customer records. There was no evidence that any of the companies that responded to the questionnaire were actively doing this.

Key finding 5: From the responses to the questionnaire, companies are not significantly using the Internet as an instrument for sharing information about their customers within their organisations.
Perhaps one of the most enlightening findings from the survey was the extent and pace of change taking place within different organisations as a result of using the Internet for interactive marketing. Even more interesting, however, was the scale of change taking place within the same industry sector. Within the financial services sector, for example, responses ranged from minimal change through to one company completely re-engineering itself.

This highlights the different levels of importance that companies are placing on interactive marketing. Evidence from the response to questions that were intended to gauge the success or otherwise of using the Internet for marketing purposes suggests there are no significant variances, perhaps further emphasising the point that companies have failed to measure or understand the impact the Internet has had on their organisations. One company, however, interestingly surmised that it was unclear whether the changes that had taken place within their company were a result of a direct response to interactive marketing, or had just happened to coincide with the start of use of the Internet.

Of the companies that responded to the questionnaire, none had integrated their use of the Internet with the rest of their business. This could indicate that companies are still unsure as to how to leverage the Internet's characteristics into their core business. Alternatively, it may indicate that companies still view the Internet as only appealing to certain types of customers, so they are just using it to target those select segments. On the other hand, some companies are almost being forced into having an Internet presence just to keep up with their competitors. Some of these companies are unlikely to fully understand the Internet's potential and are using it in a defensive way just to stay in business. The more astute 
entrepreneurs, however, are likely to exploit the Internet's capabilities for competitive advantage from day one. The rapid pace at which companies have started their Internet activities is also likely to be a contributing factor as to why companies have not yet fully implemented these activities into their core business.

Key finding 6: Over time, it is anticipated that the Internet will be seen just as any other channel, and to become more mainstream (eg similar to the way in which call centres have been integrated into many organisations).

In summary, the Internet is an excellent channel for communicating with customers on an individual basis because of its immediate and direct interaction capability. E-mail, websites, newsgroups and e-commerce transactions all provide opportunities for developing, enhancing and retaining relationships with new and existing customers. Moreover, the Internet is not a barrier to fostering close relationships between buyers and sellers. While some companies have started to use the Internet for one-to-many communications (ie outward communication), most have not yet exploited the communication capability fully for many-to-many communications (ie inward and outward communication) that the Internet offers. Even fewer companies have benefited as a result of any increased communication in getting to know their customers better. In spite of this, companies have managed to increase cross-selling opportunities through using the Internet. There is evidence, however, to suggest that when the Internet as a channel is fully integrated into a business's overall strategy, there is even greater potential for increased cross-selling.

Service is now an integral function for all organisations. The Internet has allowed companies to increase customer satisfaction through the Internet's hours of accessibility (24 hours a day, seven days a week). Companies have once again not fully exploited this 'permanent open window' into their organisations. Opportunities exist to make greater use of companies' websites, for example in providing customer support services, particularly when companies' offices, branches or call centres may be closed.

The Internet has the potential to be used as an effective tool for collecting, storing and disseminating information about customers internally within organisations. Any such data, however, need to be linked with other forms of customer information amassed via alternative channels, to provide a single consolidated view of individual customers' preferences.

The Internet is being used in many companies as a catalyst for change. The pace and extent of such change, however, differs significantly from company to company. Some have launched completely new business ventures that are entirely Internet-based; others are still at the experimental stage, whereas one has re-engineered all its channels of business as a result of the Internet. None of the companies that responded to the questionnaire have yet fully amalgamated their Internet offerings with their conventional business offerings. It is expected that this will happen over time, although the pace at which companies will make this transition will differ from organisation to organisation.

Stone et al. ${ }^{42}$ probably offer the best summary of the majority view of the companies that responded to the survey in terms of their attitude to the Internet. They state:

'until recently most large customers have kept their Internet activities un-integrated with their core commercial processes, but some expect to 
integrate and eventually re-engineer their processes around it, if their experiments deliver the quantity and quality of customer interaction they desire.'

Most companies have not yet fully realised the benefits they perceive they can attain through their use of the Internet. All the companies that responded to the questionnaire agreed that the Internet has a very significant potential as a mainstream channel for business. By its very nature the Internet, however, has unique characteristics that need to be understood by marketers to enable them to exploit fully the opportunities that exist.

\section{DISCUSSION}

The findings reported here are based on a relatively small sample of businesses, all of which were clients of Prime

Response. All the respondents could also be classified as being corporate companies operating in the business-to-consumer sector. As such, these findings could not necessarily be interpreted as being reflective of all businesses. Thus it would be beneficial to repeat the research, but over a wider population. To glean a more generic perspective of businesses, the research should also be targeted at different markets (ie business-to-business), different sizes of businesses (in terms of employees and turnover), and companies that do not presently use customer relationship management computer software.

The dynamics of the business-to-business market and its different characteristics indicate that research into companies in this market may produce interesting results. Bingham and Raffield believe buyer-seller relationships in the business-to-business market tend to be much closer than those typically found in business-to-consumer markets. ${ }^{43}$

Companies that supply

business-to-business products or services are, therefore, likely to practice some of the characteristics of relationship marketing already.

They may also have different drivers for their adoption of the Internet as a channel and place greater emphasis on some or all of the Internet's characteristics compared with business-to-consumer companies. In this study, the most valued Internet characteristic viewed by the respondents was the Internet's ability to provide immediate and direct interaction. In the business-to-business market, this may not necessarily be the most important characteristic; for example, negotiations for potential purchases tend to be more complex than business-to-consumer purchases, ${ }^{44}$ thus potentially removing the requirement in the business-to-business market to have instantaneous access.

Moreover, companies in the business-to-business market may not place such great importance on the Internet being accessible 24 hours a day, seven days a week. This was the second most valued characteristic that emerged from the research. Comparing the typical electronic banking offerings of one large financial services company supports this view. Its business-to-business electronic banking service is currently available from 03:00 to 22:00 Monday to Friday, with even shorter hours of accessibility over the weekend. In comparison, the same financial services company's business-to-consumer electronic banking service is available 24 hours a day, seven days a week. The hours of availability presumably reflect the likelihood of each of the respective services being used, with the premise that customers of the business-to-business service do not demand the same hours of accessibility as 
customers using the business-to-consumer service.

As inferred in the research findings, it would be interesting to research smaller-sized companies to see if this is an area in which they can aggressively compete with larger-sized organisations. For example, smaller-sized companies are more likely to be able to make the transition to adoption of the Internet as a mainstream channel faster than larger companies can. Their size should therefore be an advantage in the race to make any changes, but having fewer funds and less expertise to make the transition may be a disadvantage. Mathur, Mathur and Gleason posit 'investors have more confidence in the Internet efforts by firms that have already demonstrated their superior financial performance ... financially better performing firms should therefore definitely make the Internet an integral component of their services marketing strategies'. ${ }^{45}$ This would suggest the attempts of smaller-sized companies and start-up companies may be hindered, and the upper hand will remain with more established and strong performing businesses.

The research would also benefit in targeting companies in a wider selection of business sectors. Almost two-thirds of the companies who responded in this study were operating in financial services, with the remainder split across the retail, transport and automobile sectors. Clearly, researching a much broader range of business sectors would generate insights into trends that may be happening within other sectors.

Much has been written independently about the Internet and relationship marketing, whereas there is a dearth of prior published literature comparing these two phenomena. The findings from this research therefore provide specific evidence of how the Internet and relationship marketing techniques can be used and the business benefits that can be realised.

The findings from this research themselves provide a benchmark that subsequent researchers can use to compare their results at a later date. One of the most significant findings from this research was the varying pace of change taking place within different companies looking to develop their Internet offerings. It would therefore be extremely revealing to repeat the research and measure the speed of change within those same companies at some time in the near future. Through such research, it should be possible to illustrate the scope of any changes, as companies mobilise their efforts to meet the challenges that the Internet presents.

Therefore, is the Internet a fad or a fundamental for relationship marketing? This study has demonstrated that it is possible to combine relationship marketing techniques with the Internet, which implies that the Internet is both a fad and a fundamental for relationship marketing.

It is a fad at the moment because the Internet in general is topical and there is much activity in the commercial world revolving around it. Using relationship marketing techniques with the Internet will not materialise into substantial benefits, however, unless marketers really understand the capabilities of the Internet and use it for what it is good at communication. It is also a fundamental; there are significant benefits that can be realised from using relationship marketing techniques with the Internet, as already highlighted. The key to maximising returns from using the Internet for relationship marketing is to ensure the Internet is an integral part of a business's overall strategy and, as a channel, is managed in conjunction with all other channels that a business uses. 
The Internet will continue to be developed as a channel for business. Those companies that are able to exploit its strengths and align its use with the rest of their business are more likely to succeed than those who use it in a misguided fashion. Relationship marketing is not synonymous however with the Internet. It is a technique that can be and often is applied to businesses that use other more traditional channels. Companies looking to use the Internet for relationship marketing purposes, however, need to do so in conjunction with the rest of their overall business strategy. Relationship marketing is just one technique that companies can use to successfully develop their Internet offerings.

\section{References}

1 Geller, L. K. (1998) 'The Internet: The ultimate relationship marketing tool', Direct Marketing, Vol. 61, No. 5, pp. 36-38.

2 Baker, M. J. (1996), 'Marketing: An introductory text' (sixth edition), Macmillan Press, Basingstoke.

3 Jobber, D. (1995) 'Principles and practice of marketing', McGraw-Hill, Maidenhead.

4 Christopher, M., Payne, A. and Ballantyne, D. (1991) 'Relationship marketing', Butterworth-Heinemann, Oxford

5 McCarthy, E. J. (1960) 'Basic marketing', Irwin Professional, Illinois.

6 Borden, N. (1964) 'The concept of the marketing mix', Journal of Advertising Research, June, pp. 2-7.

7 Christopher, Payne and Ballantyne (1991) op. cit.

8 Peltier, J. W., Schibrowsky, J. A. and Davis, J. (1998) 'Using additional and descriptive database information to understand interactive buyer-seller relationships', Journal of Interactive Marketing, Vol. 12, No. 3, pp. 32-45.

9 O’Mally, L., Patterson, M. and Evans, E. (1999) 'Exploring direct marketing', International Thomson Business Press, London.

10 Gronroos, C. (1996) 'Relationship marketing: Strategic and tactical implications', Management Decision, Vol. 34, No. 3, pp. 5-15.

11 ibid.

12 Hamill, J. and Gregory, K. (1997) 'Internet marketing in the internationalisation of UK SMEs', Journal of Marketing Management, Vol. 13, pp. 9-28.

13 Ellsworth, J. H. and Ellsworth, M. V. (1996) 'The new Internet business book', John Wiley \& Sons, Canada.

14 Kressin, M. (1997) 'The Internet and the World
Wide Web', Prentice-Hall, New Jersey.

15 Gronroos (1996) op. cit.

16 Hagel, J. (1999) 'Net gain: Expanding markets through virtual communities', Journal of Interactive Marketing, Vol. 13, No. 1, pp. 55-65.

17 Gronroos (1996) op. cit.

18 Ellsworth and Ellsworth (1996) op. cit.

19 Parsons, A., Zeisser, M. and Waitman, R. (1998) 'Organising today for the digital marketing of tomorrow', Journal of Interactive Marketing, Vol. 12, No. 1, pp. 31-46.

20 Hoffman, D. L. and Novak, T. P. (1996) 'Marketing in hypermedia computer-mediated environments: Conceptual foundations', Journal of Marketing, Vol. 60, No. 3, pp. 50-69.

21 Prime Response is one of the leading suppliers of database marketing software specifically designed for customer relationship management.

22 NUA Internet Surveys (1999) 'Email now primary reason people go online', available from http://www.nua.ie/surveys/.

23 NUA Internet Surveys (1999) 'Email — a powerful marketing tool' available from http://www.nua.ie/surveys/, accessed 28th November, 1999.

24 Stacey, R. (1993) 'The many benefits of relationship marketing', Direct Marketing, Vol. 56, No. 5, pp. 68-70.

25 Peltier, Schibrowsky and Davis (1998) op. cit.

26 Bulger, D. W. (1999) 'The evolution of relationship marketing: Reaching an audience of one', Direct Marketing, Vol. 61, Iss. 12, pp. 54-57.

27 Peppers, D., Rogers, M. and Dorf, B. (1999) 'Is your company ready for one-to-one marketing', Harvard Business Review, Vol. 77, Iss. 1, pp. 151-152.

28 Nicovich, S. and Cornwell, T. B. (1998) 'An Internet culture?: Implications for marketing', Journal of Interactive Marketing, Vol. 12, No. 4, pp. 22-33.

29 Christoper, Payne and Ballantyne (1991) op. cit

30 Peltier, Schibrowsky and Davis (1991) op. cit.

31 Gronroos (1996) op. cit.

32 Payne, A., Christopher, M., Clark, M. and Peck, H. (1995) 'Relationship marketing for competitive advantage', Butterworth-Heinemann, Oxford.

33 Comer, J. M., Mehta, R. and Holmes, T. L. (1998) 'Information Technology', Journal of Interactive Marketing, Vol. 12, No. 2.

34 Ganesan, S. (1994) 'Detriments of long-term orientation in buyer-seller relationships', Journal of Marketing, Vol. 58, pp. 1-19.

35 Ruekert, R. W. and Churchill, G. A. Jr. (1984) 'Reliability and validity of alternative measures of channel member satisfaction', Journal of Marketing Research, Vol. 21, pp. 226-233.

36 Stone, M., Byrne, S., Knight, G., Loader, G. and Thompson, H. (1998) 'The future of relationship marketing: Towards transparent marketing?', Journal of Database Marketing, Vol. 6, No. 1, pp. 11-23.

37 Forrester Research (1997) 'Business trade and 
technology services', available from http://www.forrester.com/1997/reports/ nov97btr.htm, accessed June 1999

38 Jacquelot, P. (1999) 'Ups and downs of Internet banking' available from

http://www.ft.com/specials/sp2e76.htm, accessed 12th December, 1999.

39 Likert, R. (1932) 'A technique for measurement of attitudes', Archives of Psychology, No. 140.

40 Peltier, Schilbrowsky and Davis (1998) op. cit.
41 Stone et al. (1998) op. cit.

42 ibid.

43 Bingham, F. G. Jr. and Raffield, B. T. III. (1990) 'Business to business marketing management', Richard D. Irwin, Illinois, USA.

44 ibid.

45 Mathur, L. K., Mathur, I. and Gleason, K. C. (1998) 'Services advertising and providing services on the Internet', Journal of Services Marketing, Vol. 12 , Iss. 5. 